\title{
Fourth atom-bond connectivity index of an infinite class of Nanostar Dendrimer $\mathrm{D}_{3}[\mathrm{n}]$
}

\section{Mohammad Reza Farahani}

Department of Applied Mathematics, Iran University of Science and Technology (IUST),

Narmak, Tehran 16844, Iran

\section{ABSTRACT}

Mr_Farahani@Mathdep.iust.ac.ir

The atom-bond connectivity (ABC) index of a graph $G$ is a connectivity topological index was defined as $A B C(G)=\sum_{e=u v \in E(G)} \sqrt{\frac{d_{u}+d_{v}-2}{d_{u} d_{v}}}$, where $d_{v}$ denotes the degree of vertex $v$ of $G$. In 2010, M. Ghorbani et. al. introduced a new

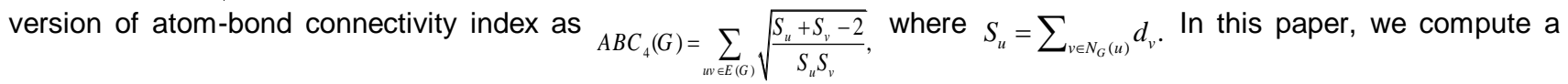
cloused formula of $A B C 4$ index of an infinite class of Nanostar Dendrimer $D_{3}[n]$. A Dendrimer is an artificially manufactured or synthesized molecule built up from branched units called monomers.

\section{Indexing terms/Keywords}

Molecular graph; Chemical graph theory; Nanostar Dendrimers; Atom bond connectivity index; $A B C_{4} I_{\text {Index. }}$

\section{SUBJECT CLASSIFICATION}

E.g. Mathematics Subject Classification; 05C05, 05C12

\section{Council for Innovative Research}

\author{
Peer Review Research Publishing System
}

Journal: Journal of Advances in Chemistry

Vol 4, No.1

editor@cirworld.com

www.cirworld.com, member.cirworld.com 


\section{INTRODUCTION}

Let $G=(V ; E)$ be a simple molecular graph without directed and multiple edges and without loops, the vertex and edge sets of which are represented by $V=V(G)$ and $E=E(G)$, respectively. In chemical graphs, the vertices correspond to the atoms of the molecule, and the edges represent the chemical bonds. Also, if $e$ is an edge of $G$, connecting the vertices $u$ and $v$, then we write $e=u v$ and say " $u$ and $v$ are adjacent". A connected graph is a graph such that there is a path between all pairs of vertices.

Chemical graph theory is an important branch of mathematics chemistry. A topological index is a real number associated with chemical constitution purporting for correlation of chemical structure with various physical properties, chemical reactivity or biological activity [1-8].

The chemical graph theory is an important branch of mathematical chemistry. In this branch, there are many molecular descriptors (or Topological Index), that have very useful properties to study of chemical molecules. A topological index is a real number associated with chemical constitution purporting for correlation of chemical structure with various physical properties, chemical reactivity or biological activity. Among topological descriptors, connectivity indices are very important and they have a prominent role in chemistry.

First connectivity index introduced in 1975 by Milan Randić [9], who has shown this index to reflect molecular branching and called the branching index, that later became the well-known Randić connectivity index and defined as:

$$
\chi(G)=\sum_{e=u v \in E(G)} \frac{1}{\sqrt{d_{u} d_{v}}}
$$

where $d_{u}$ denotes $G$ degree of vertex $u$.

In 2009 , Furtula et al. $[10,11]$ introduced atom-bond connectivity $(A B C)$ index, which it has been applied up until now to study the stability of alkanes and the strain energy of cycloalkanes. This index is defined as follows:

$$
A B C_{1}(G)=\sum_{u v E(G)} \sqrt{\frac{d_{u}+d_{v}-2}{d_{u} d_{v}}} .
$$

In 2010, M. Ghorbani et. al. introduced a new version of atom-bond connectivity $\left(A B C_{4}\right)$ index as [12]

$$
A B C_{4}(G)=\sum_{u v \in(G)} \sqrt{\frac{S_{u}+S_{v}-2}{S_{u} S_{v}}},
$$

where $S_{u}=\sum_{v \in N_{G}(u)} d_{v}$ and $N_{G}(u)=\{v \in V(G) \mid u v \in E(G)\}$. For further research on these connectivity indices see paper series [13-18].

Dendrimers are one of the main objects of Nano biotechnology. Here a dendrimer is a synthetic 3-dimensional macromolecule that is prepared in a step-wise fashion from simple branched monomer units, the nature and functionality of which can be easily controlled and varied.

Dendrimers are now considered to be one of the prime nanometer-scale building blocks for the construction of nanoscale objects, molecular devices and molecular 'machines', advanced drug-delivery systems, etc.

Dendrimers are one of the main objects of Nano biotechnology and is a part of a new group of macromolecules that seem photon funnels just like artificial antennas and also, it is a great resistant of photo bleaching. The Nanostar dendrimer promises to have great applications but first the structure and the energy transfer mechanism must be understood.

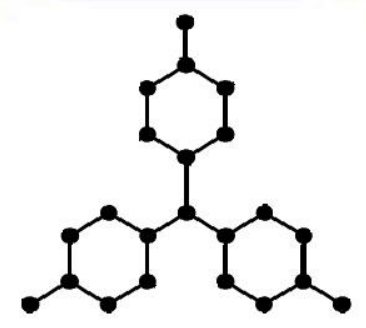

Fig 1. $D_{3}[0]$ is the primal structure of nanostar dendrimer $D_{3}[n][18]$.

In this paper, for every infinite integer $n D_{3}[n]$ denotes the $n^{\text {th }}$ growth of nanostar dendrimer. In following figures, a kind of $3^{\text {th }}$ growth of dendrimer and $D_{3}[0]$ are shown. 


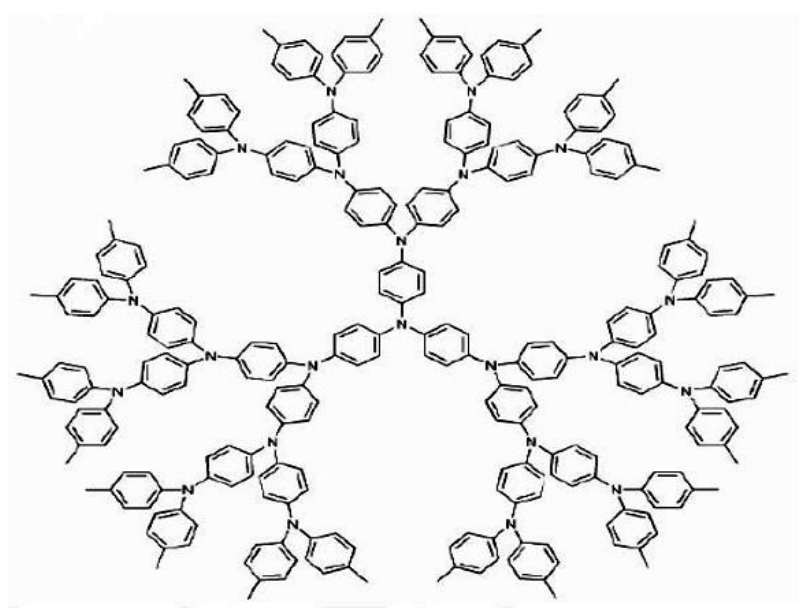

Fig. 2 The 2-Dimensional of a kind of 3th growth of dendrimer $D_{3}$ [3] [18].

For further study on this topic, we encourage the reader to consult papers [18-27]. In this paper, we continue this work to compute the fourth atom-bond connectivity index of this infinite class of Dendrimer $D_{3}[n]$.

\section{Main Results and Discussions}

In this section we compute the truncated $A B C 4$ index of an infinite class of nanostar dendrimers and we have following theorems, immediately.

Theorem. 1. Consider Nanostar Dendrimer $D_{3}[n]$ for every $n \geq 0$, then the fourth atom-bond connectivity index of $D_{3}[n]$ is equal to

$$
A B C_{4}\left(D_{3}[n]\right)=\left(\frac{41 \sqrt{2}}{5}+\frac{3 \sqrt{10}}{5}+\frac{12 \sqrt{14}}{7}+\frac{8}{3}\right)\left(2^{n}\right)-\left(\frac{12 \sqrt{2}}{5}+\frac{8 \sqrt{14}}{7}+\frac{8}{3}\right)
$$

Proof. Let $D_{3}[n]$ be the nanostar dendrimer $\forall n \in \square$. (Figures 1 and 2). This nanostar dendrimer, we define an element as Figure 3 by "Leaf", every Leaf consist of a cycle $C_{6}$ or chemically Benzene and add $3\left(2^{n}\right)$ leafs to $D_{3}[n-1]$ in the $n^{\text {th }}$ growth.

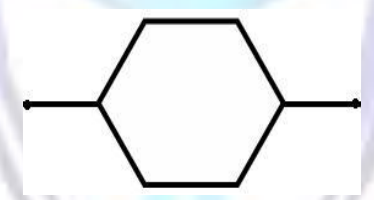

Fig. 3 "Leaf", the added graph in each branch of $D_{3}[n]$.

Therefore, there exist the number of leafs $\left(C_{6}\right)$ is equal to $\xi_{n}=3 \sum_{i=0}^{n}\left(2^{i}\right)=3\left(\frac{2^{n+1}-1}{2-1}\right)=6\left(2^{n+1}-1\right)$ in dendrimer $D_{3}[n]$.

Thus the number of vertices/atoms in this nanostar is equal to $/ V\left(D_{3}[n]\right) \mid=24\left(2^{n}\right)-20$. Also, we denote the number of all vertices as degree $i(i=1,2,3)$ of dendrimer $D_{3}[n]$ with $V_{i}[n]$. So, by according to the 2-Dimensional of dendrimer $D_{3}[n]$ in Figure 2, one can see that $\left|V_{1}[n]\right|=3\left(2^{n}\right),\left|V_{2}[n]\right|=12\left(2^{n+1}-1\right),\left|V_{3}[n]\right|=15\left(2^{n}\right)-8$ and obviously the number of edges/bonds is

$$
\left|E\left(D_{3}[n]\right)\right|=\frac{3\left(2^{n}\right)+2 \times\left[24\left(2^{n}\right)-12\right]+3 \times\left[15\left(2^{n}\right)-8\right]}{2}=24\left(2^{n+1}-1\right)
$$

New we can divide the edge/bond set $E\left(D_{3}[n]\right)$ in three partitions

And

$$
\begin{aligned}
& E_{6}=\left\{u v \in E\left(D_{3}[n]\right) / d_{u}=d_{v}=3\right\} \\
& E_{5}=\left\{u v \in E\left(D_{3}[n]\right) / d_{u}=3 \& d_{v}=2\right\} \\
& E_{4}=\left\{u v \in E\left(D_{3}[n]\right) / d_{u}=d_{v}=2 \text { or } d_{u}=3 \& d_{v}=1\right\}
\end{aligned}
$$

From Figure 2, it is easy to see that the size of edge/bond partitions $E_{4}, E_{5}$ and $E_{6}$ are equal to $15\left(2^{n}\right)-6,12\left(2^{n+1}-1\right)$ and $9\left(2^{n}\right)-6$, respectively.

From Figure 4, one can see that for every vertex $v \in V_{1}$ (hydrogen $(\mathrm{H})$ atom), $S_{v}=d_{u}=3$. For every vertex $u \in V_{3}$ $S_{u}=d_{v}+d_{u 1}+d_{u 2}=1+2+2=5$. For vertices $u_{1}, u_{2}, w_{1}, w_{2} \in V_{2}, S=5$, since for $u_{i}^{\prime} \mathrm{s}$ (or $w_{i}^{\prime} \mathrm{s}$ ) adjacent vertices are $u, w_{i}$ (or $u_{i}$ ) with $d_{u}=3$ and $d_{w i}=2$. Whereas for every vertex $u^{\prime} \in V_{3} S_{u^{\prime}}=d_{w}+d_{w 1}+d_{w 2}=3+2+2=7$. Finally for all others vertices $w w$ (nytrogen $(\mathrm{N})$ atom) in $V_{3}, S_{w}=3 \times 3=9$, since all its adjacent vertices are from $V_{3}$. 
Now, $\forall n \geq 0$, we have computations for the fourth atom-bond connectivity index of Nanostar Dendrimer $D_{3}[n]$ as follow:

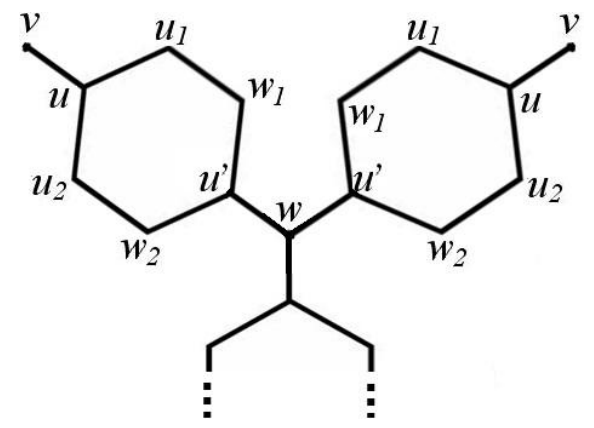

Fig. 4 A particular of 2D Lattice in a branch of $D_{3}[n]$.

$$
\begin{aligned}
& A B C_{4}\left(D_{3}[n]\right)=\sum_{u v \in E\left(D_{3}[n]\right)} \sqrt{\frac{S_{u}+S_{v}-2}{S_{u} S_{v}}} \\
& =\sum_{u v \in E_{4}} \sqrt{\frac{S_{u}+S_{v}-2}{S_{u} S_{v}}}+\sum_{\substack{u u_{i} \in E_{5} \\
\text { for }}} \sqrt{\frac{S_{u}+S_{1,2}}{S_{u_{i}} S_{u_{i}}}}+\sum_{\substack{u_{i} w_{i} \in E_{4} \\
\text { for } \\
i=1,2}} \sqrt{\frac{S_{u_{i}}+S_{w_{i}}-2}{S_{u_{i}} S_{w_{i}}}}+\sum_{\substack{u^{\prime} w_{i} \in E_{5} \\
\text { for } \\
i=1,2}} \sqrt{\frac{S_{u^{\prime}}+S_{u_{i}}-2}{S_{u^{\prime}} S_{u_{i}}}} \\
& +\sum_{w u^{\prime} \in E_{6}} \sqrt{\frac{S_{w}+S_{u^{\prime}}-2}{S_{w} S_{u^{\prime}}}}+\sum_{w w^{\prime} \in E_{6}} \sqrt{\frac{S_{w}+S_{w^{\prime}}-2}{S_{w} S_{w^{\prime}}}} \\
& =\left|V_{1}[n]\right| \sqrt{\frac{3+5-2}{3 \times 5}}+2\left|V_{1}[n]\right| \sqrt{\frac{5+5-2}{5 \times 5}}+\left(\left|E_{4}\right|-\left|V_{1}[n]\right|\right) \sqrt{\frac{5+5-2}{5 \times 5}}+\left(\left|E_{5}\right|-2\left|V_{1}[n]\right|\right) \sqrt{\frac{5+7-2}{5 \times 7}} \\
& +\left|V_{1}[n]\right| \sqrt{\frac{7+9-2}{7 \times 9}}+\left(\left|E_{6}\right|-\left|V_{1}[n]\right|\right) \sqrt{\frac{9+9-2}{9 \times 9}} \\
& =3\left(2^{n}\right) \sqrt{\frac{2}{5}}+\frac{12 \sqrt{2}}{5}\left(2^{n}\right)+\frac{12 \sqrt{2}}{5}\left(2^{n+1}-1\right)+\left(6\left(2^{n+1}\right)-8\right) \sqrt{\frac{2}{7}}+\sqrt{2}\left(2^{n}\right)+\frac{8}{3}\left(2^{n}-1\right)
\end{aligned}
$$

Here the proof is complete and $A B C_{4}\left(D_{3}[n]\right)=\left(\frac{41 \sqrt{2}}{5}+\frac{3 \sqrt{10}}{5}+\frac{12 \sqrt{14}}{7}+\frac{8}{3}\right)\left(2^{n}\right)-\left(\frac{12 \sqrt{2}}{5}+\frac{8 \sqrt{14}}{7}+\frac{8}{3}\right)$

Corollary. 1. The fourth atom-bond connectivity index of Nanostar Dendrimer $D_{3}[n]$ for all positive integer number $n$ are $\hat{A} B C_{4}\left(D_{3}[n]\right)=22.5748\left(2^{n}\right)-10.3369$.

\section{REFERENCES}

[1] R. Todeschini and V. Consonni, Handbook of Molecular Descriptors, Wiley-TUACH, Weinheim (2000).

[2] N. Trinajstić, Chemical Graph Theory, 2nd. CRC Press, Boca Raton, FL, (1992), 20-75.

[3] D.J. Klein and M. Randić. J. Mathematical Chemistry. VCH, Weinheim.(1990).

[4] I. Gutman and O.E. Polansky. Mathematical Concepts in Organic Chemistry. Springer-Verlag, New York, (1986).

[5] T. Balaban. Topological Indices and Related Descriptors in QSAR and QSPR. Gordon and Breach Science Publishers. The Netherlands(1999).

[6] M. Barysz, D. Plavi and N. Trinajstić. MATCH Commun. Math. Comput. Chem. 19, (1986), 89.

[7] M.A. Johnson and G.M. Maggiora. Concepts and Applications of Molecular Similarity. Wiley Interscience, New York(1990).

[8] H. Wiener. Structural determination of paraffin boiling points. J. Am. Chem. Soc. 69, (1947), 17.

[9] M. Randić, On characterization of molecular branching, Journal of the American Chemical Society. 97, (1975), 6609. 
[10] B. Furtula, A. Graovac and D. Vukičević, Atom-bond connectivity index of trees, Disc. Appl. Math. 157 (2009), 28282835.

[11] D. Vukičević and B. Furtula. Topological index based on the ratios of geometrical and arithmetical means of endvertex degrees of edges. Journal of Mathematics Chemical. 46, (2009), 1369.

[12] M. Ghorbani, M.A. Hosseinzadeh, Computing $A B C_{4}$ index of nanostar dendrimers. Optoelectron. Adv. Mater.-Rapid Comm. 4(9), (2010), 1419-1422.

[13] A. Graovac and M. Ghorbani. A New Version of Atom-Bond Connectivity Index. Acta Chim. Slov. 57, 609-612, (2010).

[14] M.R. Farahani. Computing a New Version of Atom-Bond Connectivity Index of Circumcoronene Series of Benzenoid $\mathrm{H}_{\mathrm{k}}$ by Using Cut Method, J. Math. Nano Science, 2. 2012 (In press).

[15] M.R. Farahani. Computing fourth atom-bond connectivity index of V-Phenylenic Nanotubes and Nanotori. Acta Chimica Slovenica. 60(2) (2013). In press.

[16] M.R. Farahani. New Version of Atom-Bond Connectivity Index of $\mathrm{TURC}_{4} \mathrm{C}_{8}(\mathrm{~S})$. International Journal of Chemical Modeling. 4(4), 527-521, (2012).

[17] M.R. Farahani. Computing Atom-Bond Connectivity $A B C_{4}$ index for Circumcoronene Series of Benzenoid. Journal of Advances in Chemistry. (2013), In press.

[18] M.R. Farahani. Some Connectivity index of an infinite class of Dendrimer Nanostars. Submitted for publish, (2013).

[19] A.R. Ashrafi and P. Nikzad. Connectivity index of the family of dendrimer nanostars. Digest. J. Nanomater. Bios. 4(2), (2009), 269-273.

[20] A. Heydari and B. Taeri. MATCH Commun Math Comput Chem, 57, (2007), 463.

[21] M. Eliasi and B. Taeri, MATCH Commun Math Comput Chem, 59, (2008), 437.

[22] A.R. Ashrafi and P. Nikzad. Kekule index and bounds of energy for nanostar dendrimers. Digest. J. Nanomater. Bios. 4(2), (2009), 383-388.

[23] S. Alikhani and M.A. Iranmanesh. Eccentric connectivity polynomials of an infinite family of dendrimer. Digest. J. Nanomater. Bios. 6(1), (2011), 256-257.

[24] M. Golriz, M.R. Darafsheh and M.H. Khalifeh. The wiener, szeged and pi-indices of a phenylazomethine dendrimer. Digest. J. Nanomater. Bios. 6(4), (2011), 1545-1549.

[25] A. Karbasioun and A.R. Ashrafi. Wiener and detour indices of a new type of nanostar dendrimers. Macedonian journal of chemistry and chemical engineering. 28(1), (2009), 49-54.

[26] D.A. Klarner. Polyominoes, In: J. E. Goodman, J. ORourke, (eds.) Handbook of Discrete and Computational Geometry. CRC Press, Boca Raton. Chapter 12, (1997), 225-242.

[27] G.R. Newkome, C.N. Moorefield and F. Vogtlen, Dendrimers and Dendrons. Concepts, Syntheses, Applications. (Wiley-VCH Verlag Gmbh \& Co. Kgaa), (2002). 